\title{
FAKTOR-FAKTOR YANG MEMPENGARUHI KELULUSAN UJI KOMPETENSI NERS INDONESIA (UKNI)
}

\author{
Muhammad Agung Krisdianto, Wiwik Kusumawati \\ Universitas Muhammadiyah Yogyakarta \\ E-mail: magungkrisdianto@gmail.com
}

\begin{abstract}
ABSTRAK
Uji Kompetensi Ners Indonesia (UKNI) merupakan capaian akhir mahasiswa keperawatan untuk dinyatakan status mereka sebagai perawat yang kompeten atau tidak. Isu UKNI sebagai exit exam semakin gencar disosialisasikan oleh Kemenristekdikti, akan tetapi saat ini angka kelulusan UKNI masih kecil. Kecilnya angka kelulusan UKNI menjadi ancaman yang besar seperti peningkatan pengangguran, keterlambatan kelulusan, hingga kalahnya persaingan perawat Indonesia terhadap perawat luar negeri. Saat ini belum ada ringkasan khusus mengenai faktor apa saja yang mempengaruhi kelulusan UKNI. Literature Review ini betujuan mengetahui faktor apa saja yang mempengaruhi kelulusan UKNI. Literature Review dilakukan dengan mesin pencari Google Schoolar. Terdapat 6 artikel jurnal yang dianalisis setelah melewati proses inklusi. Hasil analisis menyatakan bahwa persiapan dan pelaksanaan UKNI memiliki faktor-faktor dalam menentukan kelulusan UKNI.
\end{abstract}

Kata Kunci: Uji Kompetensi Ners Indonesia

\begin{abstract}
Indonesian Nurse Competency Exam (INCE) is the final achievement of nursing students to be declared their status as competent nurses or not. The issue of the INCE as an exit exam has been intensified by the Ministry of Research, Technology and Higher Education, but currently the INCE graduation rate is still small. The small number of INCE graduation is a big threat, such as an increase in unemployment, a delay in graduation, and the loss of Indonesian nurse competition to foreign nurses. At present there is no specific summary regarding what factors influence the graduation of INCE. This Literature Review aims to find out what factors influence INCE graduation. Literature Review is done with the Google Schoolar search engine. There are 6 journal articles that analyzed after going through the inclusion process. The results of the analysis stated that the preparation and implementation of INCE had factors in determining INCE graduation.
\end{abstract}

Keyword: Indonesian Nurse Competency Exam 


\section{PENDAHULUAN}

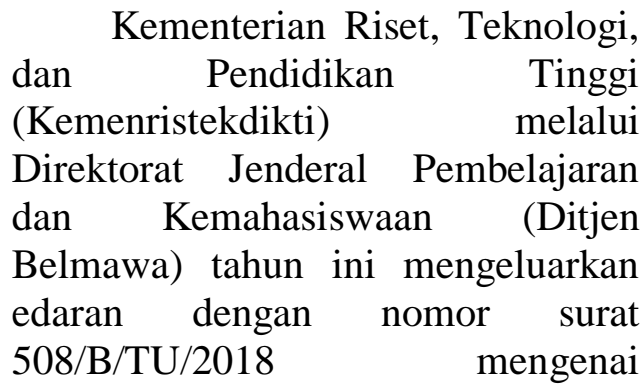

Pelaksanaan Uji Kompetensi Bidang Kesehatan Tahun 2018. Uji kompetensi adalah uji perilaku, keterampilan, dan pengetahuan yang dilakukan oleh institusi pendidikan kesehatan untuk peserta didiknya (Kemenristekdikti, 2018). Isi surat ini menjadi pro dan kontra dikalangan akademisi. Hasil konsensus poin 4 yang ditujukan kepada ketua institusi pendidikan kesehatan didalam surat ini berbunyi "Uji kompetensi nasional untuk seluruh bidang kesehatan sebagai salah satu syarat kelulusan dari pendidikan vokasi atau profesi (uji kompetensi sebagai exit exam) akan diimplementasikan mulai akhir juni 2019. Kemenristekdikti dan Kemenkes akan memfasilitasi sosialisasi dan persiapan implementasi uji kompetensi nasional bidang kesehatan sebagai exit exam.". Keputusan konsensus ini menjadi bahan kajian bagi setiap institusi pendidikan kesehatan agar dapat mempersiapkan peserta didik secara optimal untuk menghadapi uji kompetensi. Salah satu institusi pendidikan kesehatan yang terdampak adalah pendidikan keperawatan.

Uji kompetensi dalam pendidikan keperawatan disebut dengan Uji Kompetensi Ners Indonesia (UKNI). UKNI adalah uji terhadap mahasiswa keperawatan yang telah menyelesaikan pendidikan profesi (Silvestri, Nursalam, \&
Haryanti, 2016). Pendidikan keperawatan telah melaksanakan uji kompetensi dengan metode Computer Based Test (CBT) sejak tahun 2015. Hasil evaluasi UKNI periode XI tahun 2018 menunjukan bahwa angka lulusan ners yang tidak kompeten berjumlah 8.426 orang, dan kompeten berjumlah 5.975 orang (Ristekdikti, 2018). Gambaran tingginya angka tidak kompeten akan menjadi ancaman bagi mahasiswa untuk perencanaan exit exam. Peserta UKNI tidak kompeten berarti tidak dapat menjalani prosesi wisuda hingga dinyatakan kompeten, secara otomatis angka pengangguran bidang keperawatan akan semakin tinggi.

Belum ada kajian literatur yang menyimpulkan apa saja faktor-faktor yang dapat mempengaruhi kelulusan UKNI, sehingga penulis tertarik untuk membuat literature review mengenai faktor-faktor yang mempengaruhu Uji kompetensi Ners Indonesia.

\section{METODE}

Literature Review ini menggunakan metode pencarian dengan menggunakan mesin pencari Google Schoolar. Kata kunci yang digunakan dalam pencarian dan menyisakan 9 artikel. Penulis lalu membaca konten isi sehingga didapatkan 6 artikel yang kemudian akan dibahas sebagai bahan literature review (tabel 2). berdasarkan hasil, penulis melakukan inklusi dengan membaca abstrak artikel dan diapatkan 27 hasil artikel jurnal. Lalu adalah "Uji Kompetensi Ners Indonesia" 
Tabel 1. Proses Pencarian Literasi

\begin{tabular}{cc}
\hline Pencarian Data/Sortir & Hasil \\
\hline Kata Kunci “UKNI” & 27 \\
\hline Pembacaan Abstrak & 9 \\
\hline Pembacaan Konten/Isi & 6 \\
\hline
\end{tabular}

HASIL PENELITIAN

Tabel 2. Hasil Literasi

\begin{tabular}{|c|c|c|c|c|c|c|}
\hline $\begin{array}{l}\mathbf{N} \\
\mathbf{0} \\
\end{array}$ & Peneliti & Tahun & Judul & Penerbit & $\begin{array}{c}\text { Metode, } \\
\text { Variabel, } \\
\text { dan Sampel } \\
\end{array}$ & Hasil \\
\hline 1 & Alvin Abdillah & 2016 & $\begin{array}{l}\text { Analisis Faktor-Faktor } \\
\text { Yang Mempengaruhi } \\
\text { Kelulusan Uji } \\
\text { Kompetensi Ners } \\
\text { Indonesia }\end{array}$ & $\begin{array}{l}\text { Jurnal } \\
\text { Penelitian } \\
\text { Administrasi } \\
\text { Publik }\end{array}$ & $\begin{array}{l}\text { Metode: } \\
\text { Kuantitatif } \\
\text { Cross } \\
\text { Sectional } \\
\text { Variabel: } \\
\text { Independent } \\
\text { (Tryout, IPK, } \\
\text { Gaya } \\
\text { Belajarr) } \\
\text { Dependent } \\
\text { (Kelulusan } \\
\text { UKNI) } \\
\text { Sampel: } \\
\text { 59 } \\
\text { Responden } \\
\text { Dari (145 } \\
\text { Populasi/Ran } \\
\text { dom) }\end{array}$ & $\begin{array}{l}\text { Ada } \\
\text { Hubungan }\end{array}$ \\
\hline 2 & $\begin{array}{l}\text { Ayu Hartina, } \\
\text { Takdir Tahir, } \\
\text { Nurhaya } \\
\text { Nurdin, } \\
\text { Midawati } \\
\text { Djafar }\end{array}$ & 2018 & $\begin{array}{l}\text { Faktor Yang } \\
\text { Berhubungan Dengan } \\
\text { Kelulusan Uji } \\
\text { Kompetensi Ners } \\
\text { Indonesia (UKNI) Di } \\
\text { Regional Sulawesi }\end{array}$ & $\begin{array}{l}\text { Jurnal } \\
\text { Persatuan } \\
\text { Perawat } \\
\text { Nasional } \\
\text { Indonesia }\end{array}$ & $\begin{array}{l}\text { Metode: } \\
\text { Survei } \\
\text { Analitik } \\
\text { Cross } \\
\text { Sectional } \\
\text { Variabel: } \\
\text { Independent } \\
\text { (Kesiapan, } \\
\text { Tryout } \\
\text { UKNI, } \\
\text { Prestasi } \\
\text { Akademik, } \\
\text { Kondisi } \\
\text { Fisik) } \\
\text { Dependent } \\
\text { (Kelulusan } \\
\end{array}$ & $\begin{array}{l}\text { Ada } \\
\text { Hubungan: } \\
\text { Kesiapan, } \\
\text { Tryout, dan } \\
\text { Prestasi } \\
\text { Akademik } \\
\\
\text { Tidak Ada } \\
\text { Hubungan: } \\
\text { Kondisi Fisik }\end{array}$ \\
\hline
\end{tabular}




\begin{tabular}{|c|c|c|c|c|c|c|}
\hline & & & & & $\begin{array}{l}\text { UKNI) } \\
\text { Sampel: } \\
72 \\
\text { Responden } \\
\text { (Cluster) } \\
\end{array}$ & \\
\hline 3 & $\begin{array}{l}\text { Siti Kholifah, } \\
\text { Wiwik } \\
\text { Kusumawati }\end{array}$ & 2016 & $\begin{array}{l}\text { Hambatan Lulusan } \\
\text { Ners Dalam } \\
\text { Menghadapi Uji } \\
\text { Kompetensi Ners } \\
\text { Indonesia }\end{array}$ & $\begin{array}{l}\text { The } \\
\text { Indonesian } \\
\text { Journal of } \\
\text { Health } \\
\text { Science }\end{array}$ & $\begin{array}{l}\text { Metode: } \\
\text { Kualitatif } \\
\text { Analitik } \\
\text { Deskriptif } \\
\text { Variabel: } \\
\text { UKNI } \\
\text { Informan: } \\
6 \text { Orang }\end{array}$ & $\begin{array}{l}\text { Hasil: } \\
\text { Persiapan: } \\
\text { Tidak Fokus } \\
\text { Dalam } \\
\text { Belajar } \\
\text { (Sedang } \\
\text { Profesi), } \\
\text { Minim } \\
\text { Pengalaman } \\
\text { Klinik, Tidak } \\
\text { Tahu Konsep } \\
\text { UKNI (Kisi- } \\
\text { Kisi) }\end{array}$ \\
\hline & & & & & & $\begin{array}{l}\text { Pelaksanaan: } \\
\text { Memilih } \\
\text { Jawaban } \\
\text { Yang Benar, } \\
\text { Cemas, } \\
\text { Bingung/Rag } \\
\text { u-Ragu, } \\
\text { Layar Telalu } \\
\text { Terang, } \\
\text { Teknis } \\
\text { (Mouse } \\
\text { Gangguan), } \\
\text { Dukungan } \\
\text { Kelompok } \\
\text { (Beda Jadwal } \\
\text { dengan } \\
\text { Teman) }\end{array}$ \\
\hline 4 & $\begin{array}{l}\text { Deby } \\
\text { Zulkarnain } \\
\text { Rahardian } \\
\text { Syah }\end{array}$ & 2018 & $\begin{array}{l}\text { Hubungan Prestasi } \\
\text { Akademik Dan Faktor } \\
\text { Eksternal Dengan } \\
\text { Kelulusan Uji } \\
\text { Kompetensi } \\
\text { Mahasiswa } \\
\text { Keperawatan STIKES } \\
\text { Jendral Achmad Yani } \\
\text { Yogyakarta }\end{array}$ & $\begin{array}{l}\text { Jurnal } \\
\text { Keperawatan } \\
\text { Muhammadi } \\
\text { yah }\end{array}$ & $\begin{array}{l}\text { Metode: } \\
\text { Kuantitatif } \\
\text { Cross } \\
\text { Sectional } \\
\text { Variabel: } \\
\text { Independent } \\
\text { (IPK } \\
\text { Akademik, } \\
\text { IPK Ners, } \\
\text { Faktor } \\
\text { Akademik/Sa } \\
\text { rpras } \\
\text { Akademik, }\end{array}$ & $\begin{array}{l}\text { Ada } \\
\text { Hubungan: } \\
\text { IPK S1 dan } \\
\text { Faktor } \\
\text { Akademik } \\
\text { Tidak Ada } \\
\text { Hubungan: } \\
\text { IPK Ners dan } \\
\text { Faktor } \\
\text { Lingkungan }\end{array}$ \\
\hline
\end{tabular}




\begin{tabular}{|c|c|c|c|c|c|c|}
\hline & & & & & $\begin{array}{l}\text { Faktor } \\
\text { Lingkungan) } \\
\text { Dependen } \\
\text { (Kelulusan } \\
\text { UKNI) } \\
\text { Sampel: } \\
30 \\
\text { Responden } \\
\text { (Random) } \\
\end{array}$ & \\
\hline 5 & $\begin{array}{l}\text { Deby } \\
\text { Zulkarnain } \\
\text { Rahardian } \\
\text { Syah, } \\
\text { Sujono Riyadi }\end{array}$ & 2018 & $\begin{array}{l}\text { Hubungan Jenis } \\
\text { Kelamin Dan } \\
\text { Peminatan Dengan } \\
\text { Kelulusan Uji } \\
\text { Kompetensi } \\
\text { Mahasiswa Ners } \\
\text { STIKES Jenderal } \\
\text { Achmad Yani } \\
\text { Yogayakarat }\end{array}$ & $\begin{array}{l}\text { Jurnal Ilmiah } \\
\text { Kesehatan }\end{array}$ & $\begin{array}{l}\text { Metode: } \\
\text { Kuantitatif } \\
\text { Cross } \\
\text { Sectional } \\
\text { Variabel: } \\
\text { Independent } \\
\text { (Jenis } \\
\text { Kelamin dan } \\
\text { Peminatan) } \\
\text { Dependent } \\
\text { Kelulusan } \\
\text { UKNI } \\
\text { Sampel: } \\
\text { 30 } \\
\text { Responden } \\
\text { (Random) }\end{array}$ & $\begin{array}{l}\text { Tidak Ada } \\
\text { Hubungan }\end{array}$ \\
\hline 6 & $\begin{array}{l}\text { Lukmanulhaki } \\
\mathrm{m}\end{array}$ & 2018 & $\begin{array}{l}\text { Analisis Faktor Yang } \\
\text { Mempengaruhi } \\
\text { Pencapaian Kelulusan } \\
\text { Uji Kompetensi Ners } \\
\text { Pada Program Profesi } \\
\text { Ners Pada STIKES } \\
\text { Falatehan Serang }\end{array}$ & $\begin{array}{l}\text { Jurnal } \\
\text { Cakrawala } \\
\text { Pendidikan }\end{array}$ & $\begin{array}{l}\text { Metode: } \\
\text { Kuantitatif } \\
\text { Cross } \\
\text { Sectional } \\
\text { Variabel: } \\
\text { Independent } \\
\text { (Kecemasan, } \\
\text { IPK } \\
\text { Akademik, } \\
\text { Dukungan } \\
\text { Keluarga, } \\
\text { Dukungan } \\
\text { Teman } \\
\text { Sebaya, } \\
\text { Keaktifan, } \\
\text { Hasil Tryout } \\
\text { Nasional) } \\
\text { Dependent: } \\
\text { Kelulusan } \\
\text { UKNI } \\
\text { Sampel: } \\
\text { 106 } \\
\text { Responden } \\
\text { (Total) }\end{array}$ & $\begin{array}{l}\text { Ada } \\
\text { Hubungan: } \\
\text { IPK } \\
\text { Akademik, } \\
\text { Keaktifan, } \\
\text { Tryout } \\
\text { Nasional } \\
\\
\text { Tidak Ada } \\
\text { Hubungan: } \\
\text { Kecemasan } \\
\text { dan } \\
\text { Dukungan } \\
\text { Keluarga, } \\
\text { Dukungan } \\
\text { Teman } \\
\text { Sebaya }\end{array}$ \\
\hline
\end{tabular}




\section{PEMBAHASAN}

Berdasarkan hasil pencarian literatur maka didapatkan 6 artikel jurnal (tabel 2) yang memaparkan mengenai faktor apa saja yang mempengaruhi keberhasilan seseorang dalam melaksanakan Uji Kompetensi Ners Indonesia (UKNI). Hasil analisa artikel jurnal didapatkan bahwasanya keberhasilan UKNI digolongkan menjadi dua tahap yaitu Persiapan dan Pelaksanaan.

Persiapan adalah upaya untuk melengkapi atau menyiapan fisik, psikis, atau kematangan untuk mengahadapi sesuatu (Suyono \& Hariyanto, 2015). Persiapan sangat dibutuhkan dalam mengahadapi UKNI (Hartina, Tahir, Nurdin, \& Djafar, 2018). Faktor yang mempengaruhi keberhasilan UKNI dalam proses persiapan antara lain mengadakan atau mengikutsertakan mahasiswa dalam pelasanaan tryout (Abdillah, 2016; Hartina dkk., 2018; Lukmanulhakim \& Pusporini, 2018), mengetahui kemampuan mahasiswa melalaui Indeks Prestasi Kumulatif (IPK) akademik atau program S1/prestasi akademis (Abdillah, 2016; Hartina dkk., 2018; Lukmanulhakim \& Pusporini, 2018; Syah, 2018), menentukan gaya belajar yang tepat (Abdillah, 2016), persiapan yang matang (Hartina dkk., 2018), aktif dalam pembelajaran (Lukmanulhakim \& Pusporini, 2018) dan, kelengkapan sarana dan prasarana akademis (Syah, 2018). Persiapan yang matang juga dapat didapatkan dengan cara meningkatkan fokus mahasiswa terhadap UKNI selama proses Ners, memberikan kesempatan untuk menjelaskan pemaparan terhadap praktik klinis, dan mengadapakan pemahaman terhadap kisi-kisi/ blueprint UKNI (Kholifah \& Kusumawati, 2016).

Tahap kedua dalam mengetahui faktor keberhasilan UKNI adalah mengenai pelaksanaan. Pelaksanaan ialah usaha dalam mencapai atau kegiatan mewujudkan rencana yang telah dipersiapkan (Sastropoetro, 1982). Faktorfaktor keberhasilan yang berkaitan dengan pelaksanaan UKNI adalah penentuan jawaban benar, kecemasan terhadap proses pelaksanaan, kebinguan dan ragu dalam menjawab pertanyaan, permasalahan teknis seperti layar komputer yang terlalu terang dan mouse yang error, serta perbedaan ruang dengan rekan kelompok (teman satu perguruan tinggi) (Kholifah \& Kusumawati, 2016).

Maka apabila kita gambarkan faktor apa saja yang dapat mempengaruhi keberhasilan UKNI maka kita dapat melihat sepert yang tertera pada gambar 1 .

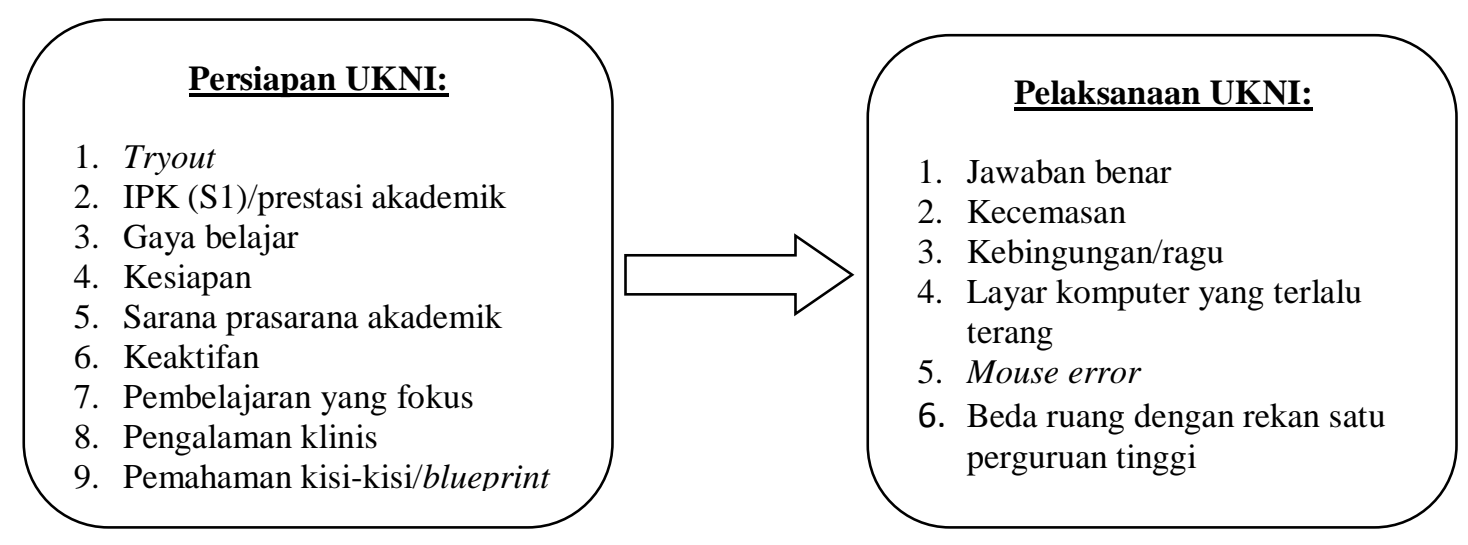

Gambar 1. Faktor Keberhasilan 


\section{SIMPULAN}

Simpulan dari literature review ini menjelaskan bahwa ada dua tahap yang dalam penentuan keberhasilan UKNI. Tahapan tersebut adalah persiapan dan pelaksanaan. Tahap persiapan meliputi, tryout, IPK akademik (S1)/prestasi akademik, gaya belajar, kesiapan, sarana prasarana akademik, keaktifan, sarana prasarana akademik, keaktifan, pembelajaran yang fokus, pengalaman klinis, pemahaman terhadap kisikisi/blueprint. Tahap pelaksanaan meliputi jawaban benar, kecemasan, kebingungan/ragu, layar komputer yang terlalu terang, mouse error, dan beda ruang terhadap rekan satu perguruan tinggi.

\section{SARAN}

Faktor persiapan dan pelaksanaan yang telah disampaikan diharapkan mampu menjadi bahan evaluasi, serta bahan kajian penelitian selanjutnya untuk meningkatkan angka kelulusan UKNI di Indonesia.

\section{DAFTAR PUSTAKA}

Abdillah, A. (2016). Analisis FaktorFaktor Yang Mempengaruhi Kelulusan Uji Kompetensi Ners Indonesia. JPAP: Jurnal Penelitian Administrasi Publik, 2(02). Diambil dari http://jurnal.untagsby.ac.id/index.php/jpap/artic le/view/996

Hartina, A., Tahir, T., Nurdin, N., \& Djafar, M. (2018). Faktor Yang Berhubungan Dengan Kelulusan Uji Kompetensi Ners Indonesia (UKNI) Di
Regional Sulawesi. Jurnal

Persatuan Perawat Nasional Indonesia (JPPNI), 2, 65. https://doi.org/10.32419/jppni .v2i 2.84

Kemenristekdikti.

Pelaksanaan Uji Kompetensi

Bidang Kesehatan Tahun 2018. DITJEN BELMAWA.

Kholifah, S., \& Kusumawati, W. (2016). Hambatan Lulusan Ners Dalam Menghadapi Uji Kompetensi Ners Indonesia, 7(1), 8 .

Lukmanulhakim, L., \& Pusporini, L.

S. (2018). The Analysis Of Factors Influencing

Graduation Achievement In

Nurse Competence Test Of

Nurse Profession

PROGRAM. Jurnal

Cakrawala Pendidikan,

37(2).

https://doi.org/10.21831/cp.v $37 i 2.19881$

Ristekdikti. (2018). Statistik Uji

Kompetensi Tahun 2018. http://ukners.dikti.go.id/pages /statistik_lulus. Jakarta.

Sastropoetro, S. (1982). Pelaksanaan Pelatihan. Jakarta: Gramedia. Silvestri, L. ., Nursalam, \& Haryanti, F. (2016). Saunders 360 Review Untuk Uji Kompetensi Ners Indonesia (UKNI). Singapore: Elsevier Singapore Pte Ltd.

Suyono, \& Hariyanto. (2015).

Implementasi Belajar \&

Pembelajaran. Bandung: Remaja Rosdakarya.

Syah, D. Z. R. (2018). Hubungan

Prestasi Akademik Dan

Faktor Eksternal Dengan

Kelulusan Uji Kompetensi

Mahasiswa Keperawatan

Stikes Jenderal Achmad Yani Yogyakarta.

Jurnal 
Keperawatan

Muhammadiyah,

2(2).

https://doi.org/10.30651/jkm.

v2i2.985

Syah, D. Z. R., \& Riyadi, S. (2018). Hubungan Jenis Kelamin Dan Peminatan Dengan Kelulusan
Uji Kompetensi Mahasiswa Ners STIKES Jenderal Achmad Yani Yogyakarta. Journal of Health Sciences, 11(1). Diambil dari http://journal.unusa.ac.id/inde x.php/jhs/article/view/565 